Dielectric and electrical properties of $\operatorname{SrTiO}_{(3 \pm y)}-\left(\mathrm{SiO}_{2}\right)_{x}$ thin films

This content has been downloaded from IOPscience. Please scroll down to see the full text. 2005 J. Phys. D: Appl. Phys. 382446

(http://iopscience.iop.org/0022-3727/38/14/022)

View the table of contents for this issue, or go to the journal homepage for more

Download details:

IP Address: 140.113.38.11

This content was downloaded on 26/04/2014 at 11:52

Please note that terms and conditions apply. 


\title{
Dielectric and electrical properties of $\mathrm{SrTiO}_{(3 \pm y)}-\left(\mathrm{SiO}_{2}\right)_{x}$ thin films
}

\author{
Hsiu-Yu Chou ${ }^{1}$, Teng-Ming Chen ${ }^{2}$ and Tseung-Yuen Tseng ${ }^{3}$ \\ ${ }^{1}$ Department of Chemical Engineering, Ta Hwa Institute of Technology, Hsinchu, Taiwan, \\ Republic of China \\ ${ }^{2}$ Department of Applied Chemistry, National Chiao Tung University, Hsinchu, Taiwan, \\ Republic of China \\ ${ }^{3}$ Department of Electronics Engineering and Institute of Electronics, National Chiao Tung \\ University, Hsinchu, Taiwan, Republic of China \\ E-mail: tseng@cc.nctu.edu.tw
}

Received 2 March 2005, in final form 11 May 2005

Published 1 July 2005

Online at stacks.iop.org/JPhysD/38/2446

\begin{abstract}
$110 \mathrm{~nm}$ thick $\mathrm{SrTiO}_{(3 \pm y)}-\left(\mathrm{SiO}_{2}\right)_{x}$ thin films with $x=0-0.45$ were prepared on $\mathrm{Pt} / \mathrm{Ti} / \mathrm{SiO}_{2} / \mathrm{Si}$ substrates using the chemical solution deposition method and then annealed at temperatures ranging from $600^{\circ} \mathrm{C}$ to $900^{\circ} \mathrm{C}$ for $1 \mathrm{~min}$. The dielectric and electrical properties of the $\mathrm{SrTiO}_{(3 \pm y)}-\left(\mathrm{SiO}_{2}\right)_{x}$ were obviously affected by the annealing temperature and composition. The dielectric constant of the thin films increased with increasing annealing temperature and decreased with an increase in Si content while the leakage current density decreased with an increase in $\mathrm{Si}$ content. The $700^{\circ} \mathrm{C}$ annealed $\mathrm{SrTiO}_{(3 \pm y)}-\left(\mathrm{SiO}_{2}\right)_{x}$ thin film with $x=0.25$ has a suitable dielectric constant of 94.8 and a low leakage current of $1.27 \times 10^{-8} \mathrm{~A} \mathrm{~cm}^{-2}$. The time-dependent dielectric breakdown curve of the $700^{\circ} \mathrm{C}$ and $800^{\circ} \mathrm{C}$ annealed $\mathrm{SrTiO}_{(3 \pm y)}-\left(\mathrm{SiO}_{2}\right)_{x}$ films with $x=0.25$ have an expected lifetime of over 10 years at electric fields higher than $0.6 \mathrm{MV} \mathrm{cm}^{-1}$.
\end{abstract}

\section{Introduction}

Dielectrics are used as core components of the two types of devices that represent the heart of the silicon semiconductor industry. One type of device acts as the capacitor dielectric used for the storage of information in dynamic random-access memories (DRAM) and another as the transistor gate dielectric in complementary metal-oxide semiconductor (CMOS) field-effect transistor (FET) logic devices. In both cases, the thickness of the present dielectric is becoming sufficiently thin such that the leakage of currents arising from electron tunnelling through the dielectrics poses a problem. One solution to the problem is the replacement of $\mathrm{SiO}_{2}$ by an alternative insulator with a higher dielectric constant. Therefore, adopting high- $k$ dielectric materials seems to be an alternative way of providing for good electrical performances, increasing circuit density and reducing the cost as well. The high- $k$ materials for gate dielectric application should satisfy various requirements such as low leakage current, thermodynamic stability on $\mathrm{Si}$, low interface defect density, and so on. Many metal oxides with high dielectric constants from 10 to 80 have been proposed, such as $\mathrm{Ta}_{2} \mathrm{O}_{5}$ [1], $\mathrm{Al}_{2} \mathrm{O}_{3}$ [2], $\mathrm{SrTiO}_{3}$ [3],
$\mathrm{ZrO}_{2}[4]$ and $\mathrm{HfO}_{2}[5,6]$. However, some problems still remain to be solved for practical applications. In practice, the interfacial reaction still exists between oxide materials and Si. Even in the ideal case of completely eliminating interfacial reaction by using barrier layers, the structure still contains several dielectrics in series, where the lowest capacitance layer will dominate the overall capacitance and also set a limit on the equivalent oxide thickness $\left(t_{\mathrm{ox}}\right)$ value.

Perovskite-oxide films with high dielectric constants have found various applications such as capacitor dielectrics in integrated circuits, semiconductor memories, gate insulators in submicron integrated circuits, electro-optic devices and electroluminescent displays. Strontium titanate, $\mathrm{SrTiO}_{3}$ (STO) is a cubic, perovskite-type crystal with a lattice constant of $3.905 \AA$. It is electrically an insulator, and its dielectric constant is as high as 300 at room temperature. The STO thin film is a potential candidate for many electronic applications owing to its large dielectric constant, high breakdown strength and good chemical stability. STO is a possible candidate for replacing silicon dioxide as the gate dielectric material for memory and logic devices [7]. However, STO tends to crystallize at low temperature, which leads to the formation of a polycrystalline 


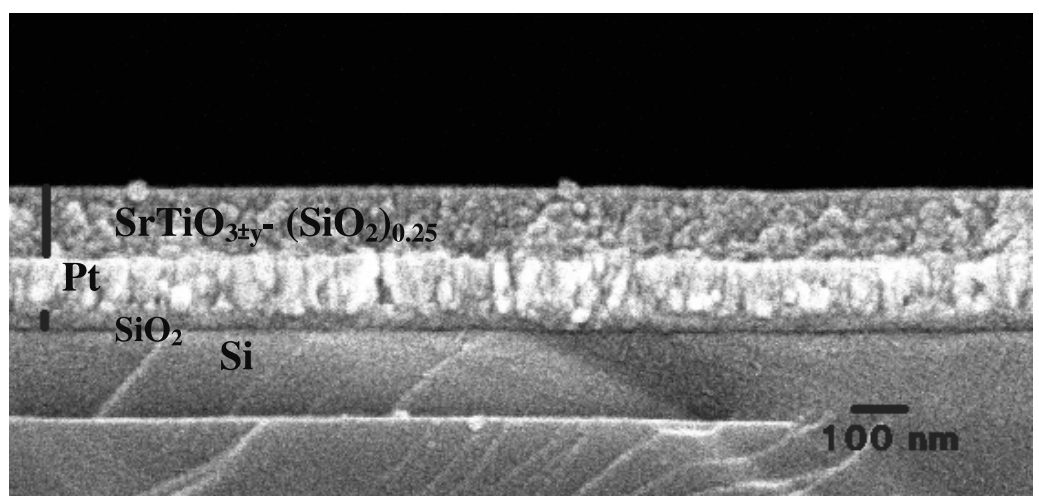

Figure 1. SEM cross-section image of $\mathrm{SrTiO}_{(3 \pm y)}-\left(\mathrm{SiO}_{2}\right)_{x}$ thin film with $x=0.25$ annealed at $800^{\circ} \mathrm{C}$.

film with crystalline grains serving as high leakage paths and with interface roughness. The retardation of the crystallization temperature has recently been demonstrated in the systems of $\mathrm{HfO}_{2}-\mathrm{SiO}_{2}$ [8] and $\mathrm{ZrO}_{2}-\mathrm{SiO}_{2}$ [9]. Such silicate dielectrics are also stable in direct contact with $\mathrm{Si}$ and have lower leakage current and better interfacial control in comparison with $\mathrm{HfO}_{2}$ and $\mathrm{ZrO}_{2}$. Keeping in mind the requirements of later generations, it is worth investigating the STO with $\mathrm{SiO}_{2}$ content in order to obtain a better understanding of its electrical and physical properties. In this paper, the electrical and dielectric properties of $\mathrm{SrTiO}_{(3 \pm y)}-\left(\mathrm{SiO}_{2}\right)_{x}$ thin films synthesized using the chemical solution deposition (CSD) method are investigated. The method shows that the leakage current density and dielectric constant of STO thin films are strongly affected by the $\mathrm{SiO}_{2}$ content.

\section{Experimental}

The $\operatorname{SrTiO}_{(3 \pm y)}-\left(\mathrm{SiO}_{2}\right)_{x}$ thin films with $x=0-0.45$ were prepared on $\mathrm{Pt} / \mathrm{Ti} / \mathrm{SiO}_{2} / \mathrm{Si}$ substrates by the CSD method. The precursor solution was made by alkoxidecarboxylate complexes. High purity strontium acetate [ $\left.\mathrm{Sr}\left(\mathrm{CH}_{3} \mathrm{COO}\right)_{2}\right]$, silicon ethoxide $\left[\mathrm{Si}\left(\mathrm{OC}_{2} \mathrm{H}_{5}\right)_{4}\right]$ and titanium ethoxide [ $\left.\mathrm{Ti}\left(\mathrm{OC}_{2} \mathrm{H}_{5}\right)_{5}\right]$ were selected as starting materials and acetic acid and ethylene glycol as solvent. Strontium acetate was initially dissolved in dehydrated acetic acid and ethylene glycol solution, which was then sealed in a reflux flask under nitrogen gas. The solution was heated to $120^{\circ} \mathrm{C}$ for $1 \mathrm{~h}$, and then titanium ethoxide and silicon ethoxide were added to the solution to form a clear and stable precursor solution at $70^{\circ} \mathrm{C}$ for $1 \mathrm{~h}$. The mole ratio of strontium to titanium was maintained at 1.0 and that of silicon to strontium was varied from 0 to 0.45 . The precursor concentration used in the study was $0.25 \mathrm{~mol}^{-1}$.

After preparation, the precursor solution was spin-coated on $\mathrm{Pt} / \mathrm{Ti} / \mathrm{SiO}_{2} / \mathrm{Si}$ substrate. The films were spin-coated on the substrates first at $2000 \mathrm{rpm}$ for $10 \mathrm{~s}$ and then at $4500 \mathrm{rpm}$ for $30 \mathrm{~s}$. The coated thin film was dried at $150^{\circ} \mathrm{C}$ for $10 \mathrm{~min}$, and then $400^{\circ} \mathrm{C}$ for $60 \mathrm{~min}$ in a conventional furnace to remove organic complex. This step was repeated twice until the desired film thickness was obtained. The thickness of the film obtained in a single spinning was about $50 \pm 5 \mathrm{~nm}$. The films with various $\mathrm{SiO}_{2}$ contents were heat treated in a rapid thermal annealing furnace at temperatures ranging from $600^{\circ} \mathrm{C}$ to $900^{\circ} \mathrm{C}$ in an oxygen atmosphere for $1 \mathrm{~min}$ with a heating rate of $150^{\circ} \mathrm{C} \mathrm{min}^{-1}$ and cooled with the same rate. The films thickness on the basis of the observation of scanning electron microscopy (SEM) is about $110 \pm 10 \mathrm{~nm}$ (figure 1). The $50 \mathrm{~nm}$ thick Pt top electrodes were then deposited on the films by sputtering through a shadow mask of an area of $9.6 \times 10^{-4} \mathrm{~cm}^{2}$.

The capacitance of the films was measured at $100 \mathrm{kHz}$ as a function of voltage from negative to positive in a metal-insulator-metal capacitor configuration with an HP 4284A impedance analyser. The dielectric constant of $\operatorname{SrTiO}_{(3 \pm y)}-\left(\mathrm{SiO}_{2}\right)_{x}$ thin films was calculated from the capacitance measured at zero bias voltage. The leakage current characteristics of $\mathrm{SrTiO}_{(3 \pm y)}-\left(\mathrm{SiO}_{2}\right)_{x}$ thin films were measured with a voltage step of $0.01 \mathrm{~V}$ and elapsed time of $30 \mathrm{~s}$ using an HP 4146C semiconductor parameter analyser. The cross-section and surface morphology of the thin films annealed at various temperatures were observed by transmission electron microscopy (TEM) and a field emission SEM (FESEM, Hitach S4700), respectively. The x-ray diffraction (XRD) patterns were recorded using a Hitachi x-ray diffractmeter with $\mathrm{Cu} \mathrm{K} \alpha$ radiation and $\mathrm{Cu}$ filter operating at a power level of $30 \mathrm{kV}, 20 \mathrm{~mA}$ in order to investigate the crystallinity and the phase of $\mathrm{SrTiO}_{(3 \pm y)}-\left(\mathrm{SiO}_{2}\right)_{x}$ thin films. The x-ray photoelectron spectroscopy (XPS) measurements were carried out in a Physical Electronics ESCA PHI 1600 spectrometer at the constant pass energy of $23.5 \mathrm{eV}$. An $\mathrm{Ar}^{+}$ion beam was used to etch the films to obtain their profiles.

\section{Results and discussion}

Figure 2 shows the XRD patterns of STO thin films annealed at various temperatures in an oxygen atmosphere. It indicates that the STO exhibits diffraction peak (110) for the thin film annealed at above $800^{\circ} \mathrm{C}$. The starting crystalline temperature of STO thin films is about $800^{\circ} \mathrm{C}$. The XRD patterns of $\operatorname{SrTiO}_{(3 \pm y)}-\left(\mathrm{SiO}_{2}\right)_{x}$ thin films with various $x$ values as deposited at $400^{\circ} \mathrm{C}$ in air indicates that no diffraction peaks of STO phase exist in the films (not shown here). Figures $3(a)$ and $(b)$ show the XRD patterns of $\mathrm{SrTiO}_{(3 \pm y)}-\left(\mathrm{SiO}_{2}\right)_{x}$ thin films with $x=0.25$ and 0.45 annealed at the temperatures indicated, respectively. The crystalline phase of $\mathrm{SrTiO}_{(3 \pm y)}-\left(\mathrm{SiO}_{2}\right)_{x}$ thin films with $x=0.25$ and 0.45 appears at annealing temperatures of about $800^{\circ} \mathrm{C}$ and $700^{\circ} \mathrm{C}$, respectively. Therefore, the crystalline temperature of $\mathrm{SrTiO}_{(3 \pm y)}-\left(\mathrm{SiO}_{2}\right)_{x}$ thin films decreases with increasing $x$ value. 


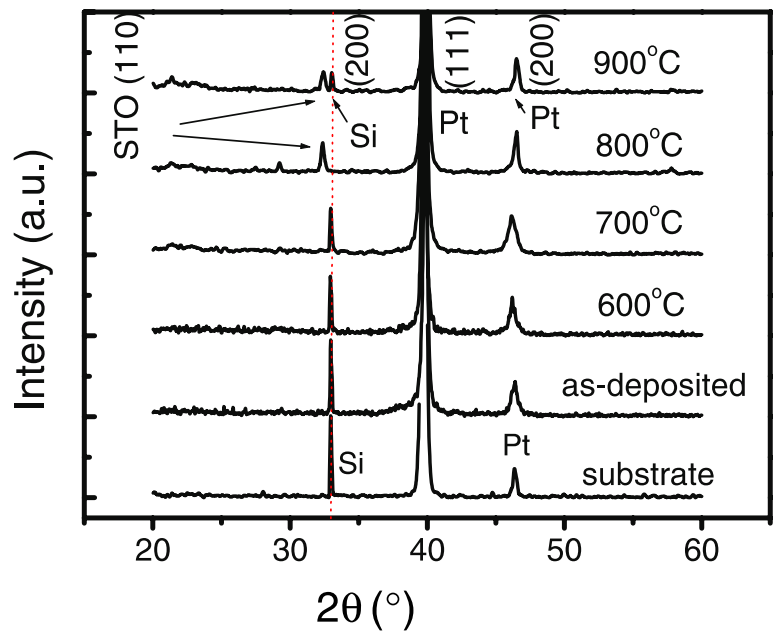

Figure 2. XRD patterns of STO thin films annealed at various temperatures.
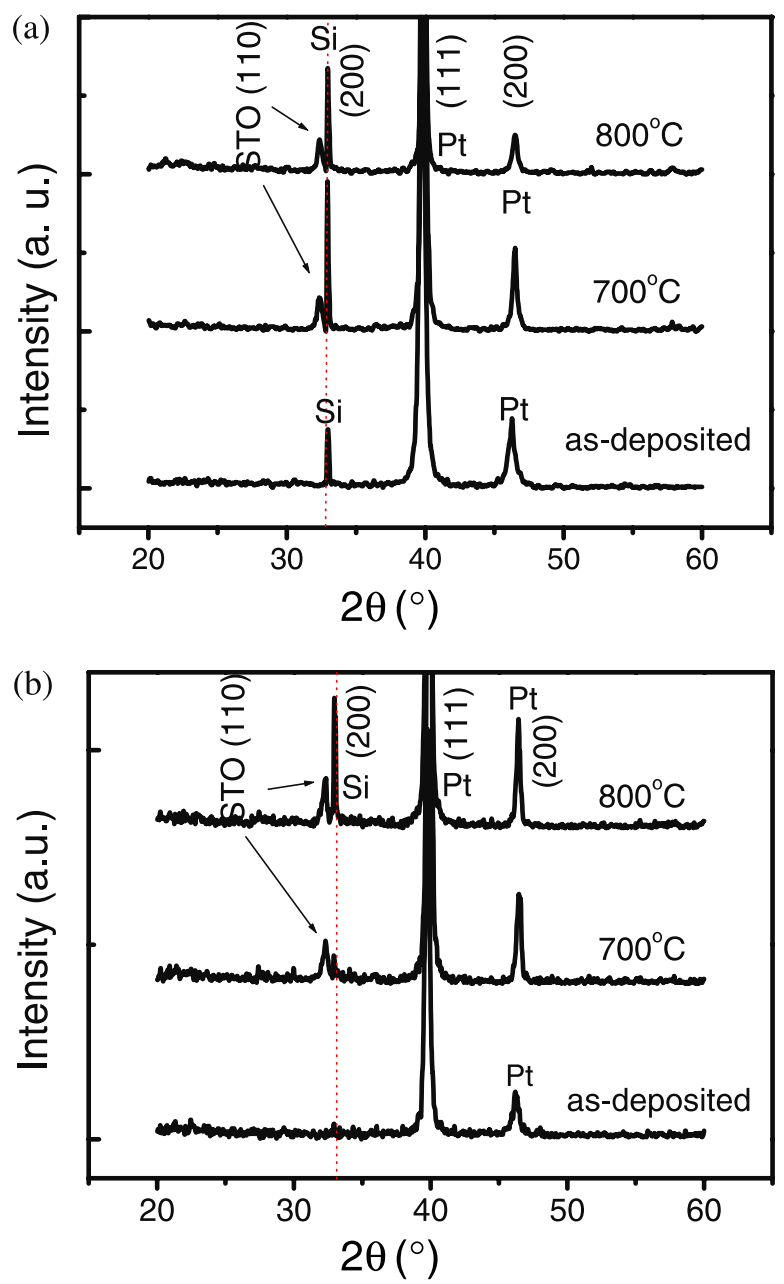

Figure 3. XRD patterns of $\mathrm{SrTiO}_{(3 \pm y)}-\left(\mathrm{SiO}_{2}\right)_{x}$ thin film with (a) $x=0.25$ and (b) $x=0.45$ as-deposited at $400^{\circ} \mathrm{C}$ and annealed at the temperatures indicated.

Figure 4 shows the typical TEM microstructure of $\mathrm{SrTiO}_{3}$ and $\mathrm{SrTiO}_{(3 \pm y)}-\left(\mathrm{SiO}_{2}\right)_{x}(x=0.25)$ thin films annealed at $800^{\circ} \mathrm{C}$, indicating the growth of the crystalline grains in both films. The selected area electron diffraction (SAED) (a)

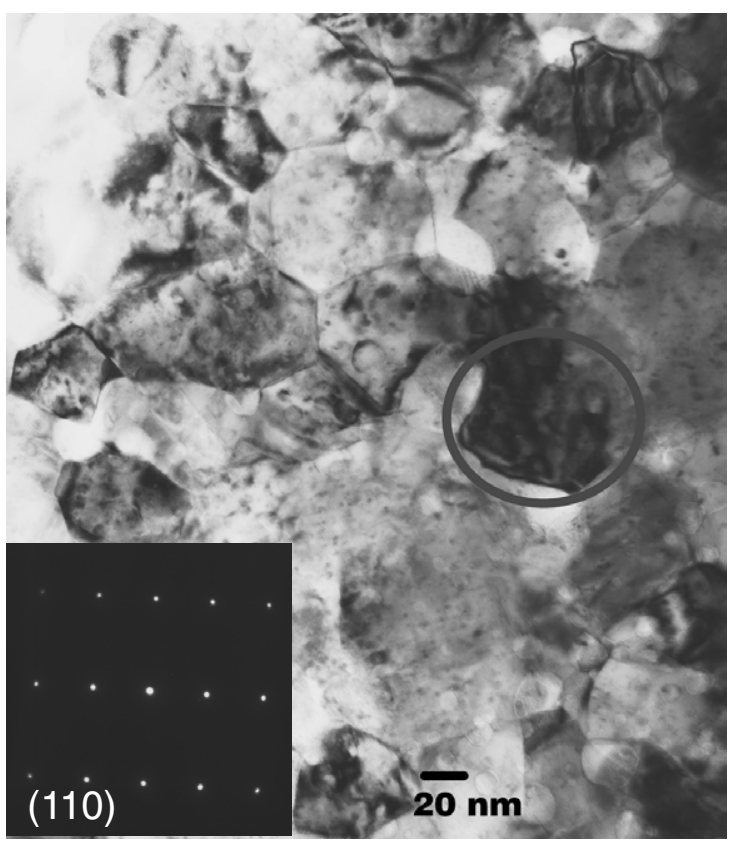

(b)

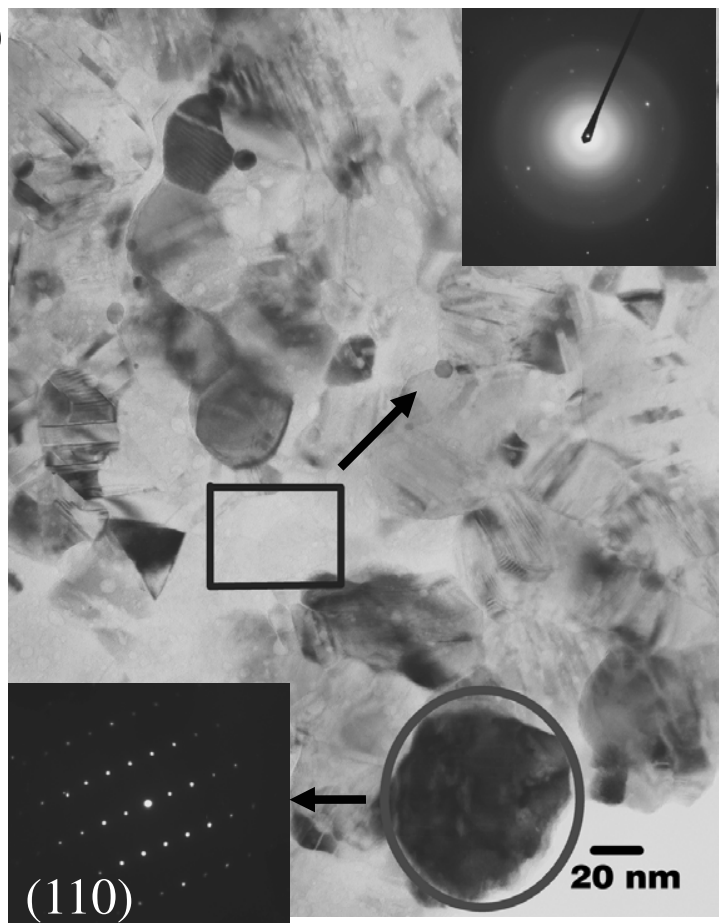

Figure 4. Typical TEM microstructure of the thin films, (a) $\mathrm{SrTiO}_{3}$, SAED pattern in inset showing (110) plane of the circle region shown in $(a),(b) \mathrm{SrTiO}_{(3 \pm y)}-\left(\mathrm{SiO}_{2}\right)_{x}$ thin film with $x=0.25$ annealed at $800^{\circ} \mathrm{C}$, SAED pattern in inset showing (110) plane of the circle region indicated in $(b)$; while another SAED pattern in inset showing amorphous structure of the boxed region indicated in $(b)$.

patterns in the insets of figures $4(a)$ and $(b)$ illustrate that the circled areas in these figures are (110) plane, which are coincident with the XRD patterns shown in figures 2 and 3. There are a smaller number of crystalline grains grown in $\mathrm{SrTiO}_{(3 \pm y)}-\left(\mathrm{SiO}_{2}\right)_{x}$ film than those grown in an STO film at the same annealing temperature. The grain sizes of STO films are larger than those of $\mathrm{SrTiO}_{(3 \pm y)}-\left(\mathrm{SiO}_{2}\right)_{x}(x=0.25)$ films 

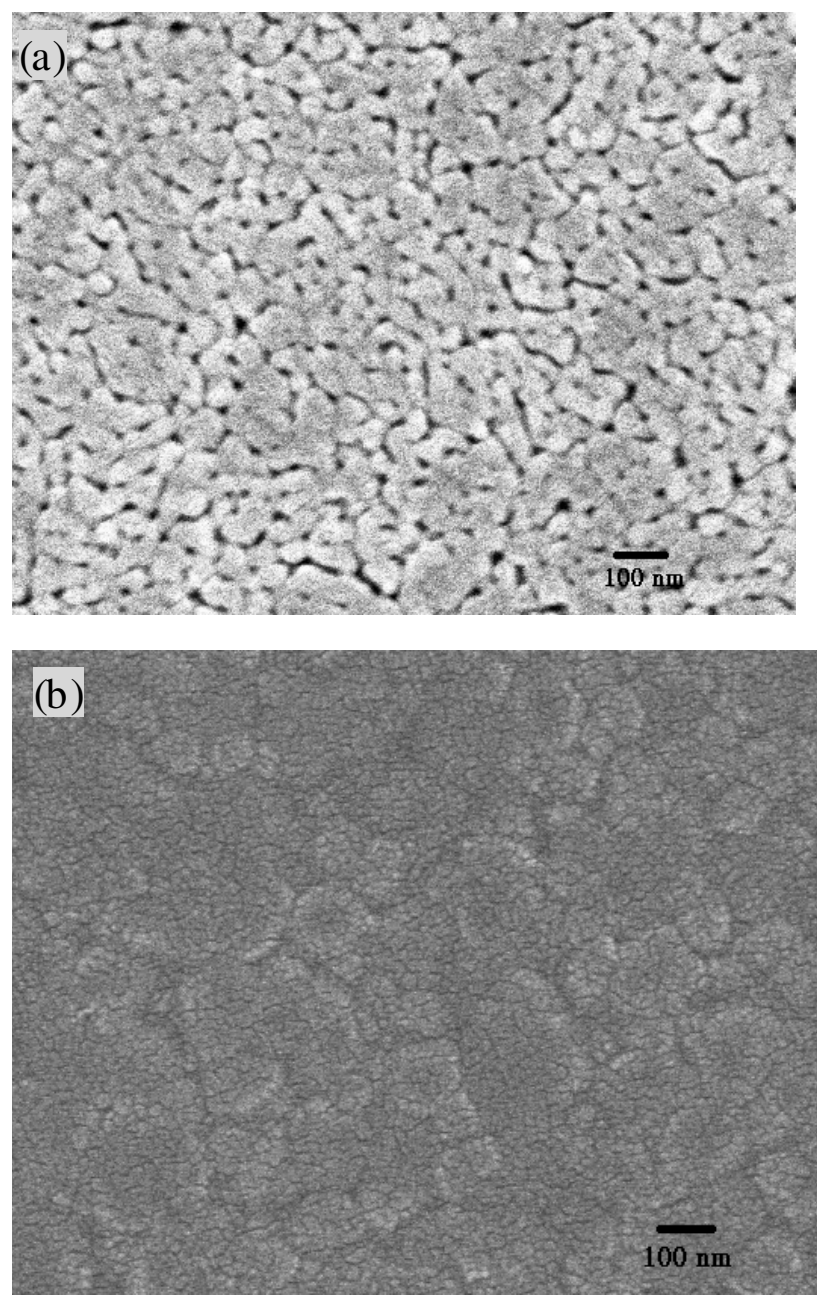

Figure 5. SEM micrographs of surface morphology of (a) STO and (b) $\mathrm{SrTiO}_{(3 \pm y)}-\left(\mathrm{SiO}_{2}\right)_{x}$ thin films annealed at $800^{\circ} \mathrm{C}$.

(figures 4(a) and (b)). Figure 4(b) also shows the coexistence of crystalline and amorphous phases (SAED pattern in the inset of this figure shows square area is amorphous phase) in the $\mathrm{SrTiO}_{(3 \pm y)}-\left(\mathrm{SiO}_{2}\right)_{x}$ thin films. Obviously, the addition of $\mathrm{SiO}_{2}$ into the films retards their crystallization.

Figures 5(a) and (b) show the SEM surface images of STO and $\mathrm{SrTiO}_{(3 \pm y)}-\left(\mathrm{SiO}_{2}\right)_{x}$ thin film with $x=0.25$ annealed at $800^{\circ} \mathrm{C}$, indicating that the addition of $\mathrm{Si}$ content would depress the growth of the grain size and improve the density of $\mathrm{SrTiO}_{(3 \pm y)}-\left(\mathrm{SiO}_{2}\right)_{x}$ thin film. Surface morphology is an important physical property which may affect the electrical properties of dielectric thin films. The $\mathrm{SrTiO}_{(3 \pm y)}-\left(\mathrm{SiO}_{2}\right)_{x}$ thin films show smoother surfaces than the STO film.

Figure 6 shows the plots of dielectric constant versus $x$ in $\operatorname{SrTiO}_{(3 \pm y)}-\left(\mathrm{SiO}_{2}\right)_{x}$ thin films annealed at various temperatures. The dielectric constant of the $\mathrm{SrTiO}_{(3 \pm y)}-\left(\mathrm{SiO}_{2}\right)_{x}$ thin films decreases with an increase in $\mathrm{Si}$ content at the same annealing temperature. However, the dielectric constant increases with increasing annealing temperature owing to the improved crystallinity of the films at higher temperature.

The addition of a low dielectric material, $\mathrm{SiO}_{2}$, into a higher dielectric matrix material, STO, results in the dielectric

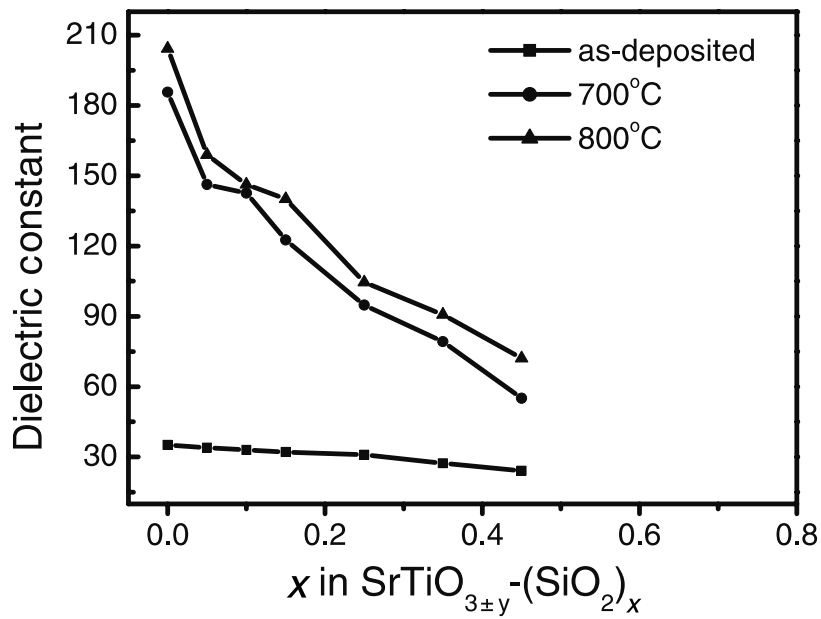

Figure 6. Dielectric constant at zero bias as a function of $x$ in $\mathrm{SrTiO}_{(3 \pm y)}-\left(\mathrm{SiO}_{2}\right)_{x}$ thin films annealed at various temperatures indicated.

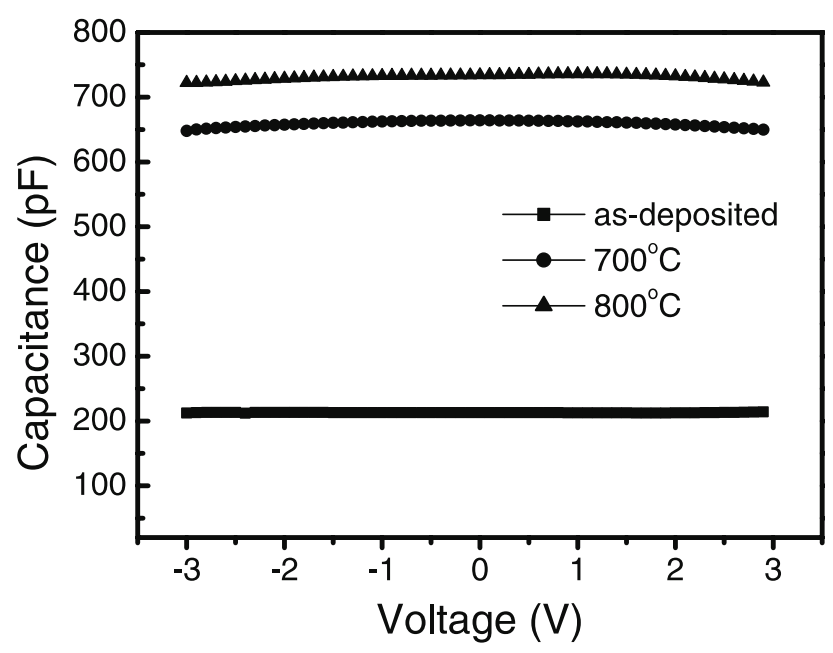

Figure 7. Capacitance versus applied voltage for $\mathrm{SrTiO}_{(3 \pm y)}-\left(\mathrm{SiO}_{2}\right)_{x}$ thin film with $x=0.25$ annealed at various temperatures indicated.

constant of the $\mathrm{SrTiO}_{(3 \pm y)}-\left(\mathrm{SiO}_{2}\right)_{x}$ thin films decreasing with increasing $\mathrm{Si}$ content.

The variation of capacitance of $\mathrm{SrTiO}_{(3 \pm y)}-\left(\mathrm{SiO}_{2}\right)_{x}$ thin films with $x=0.25$ deposited at $400^{\circ} \mathrm{C}$ and annealed at various temperatures with bias voltage is shown in figure 7 . The capacitance values keep constant with various sweep bias voltages which indicate a paraelectric property $[10,11]$.

Figure 8 depicts the leakage current density at $100 \mathrm{kV} \mathrm{cm}^{-1}$ as a function of $x$ in the $\mathrm{SrTiO}_{(3 \pm y)}-\left(\mathrm{SiO}_{2}\right)_{x}$ thin films annealed at various temperatures indicated. The leakage current density of the films decreases with increasing $x$ at the same annealing temperature. The $\mathrm{Si}$ added films with the smaller sized grains have more grain boundaries with more resistive regions than larger size grains, leading to lower leakage current. It was shown that the grain resistivity of $\mathrm{SrTiO}_{3}$ ceramic was several ohmcentimetre while that of the grain boundary was about several megaohm centimetre [12]. The grain sizes of the films with $x=0.45$ annealed at $700^{\circ} \mathrm{C}$ and $800^{\circ} \mathrm{C}$ are about $12.21 \mathrm{~nm}$ and $13.27 \mathrm{~nm}$, respectively, which were calculated by the Scherrer equation. It was also 


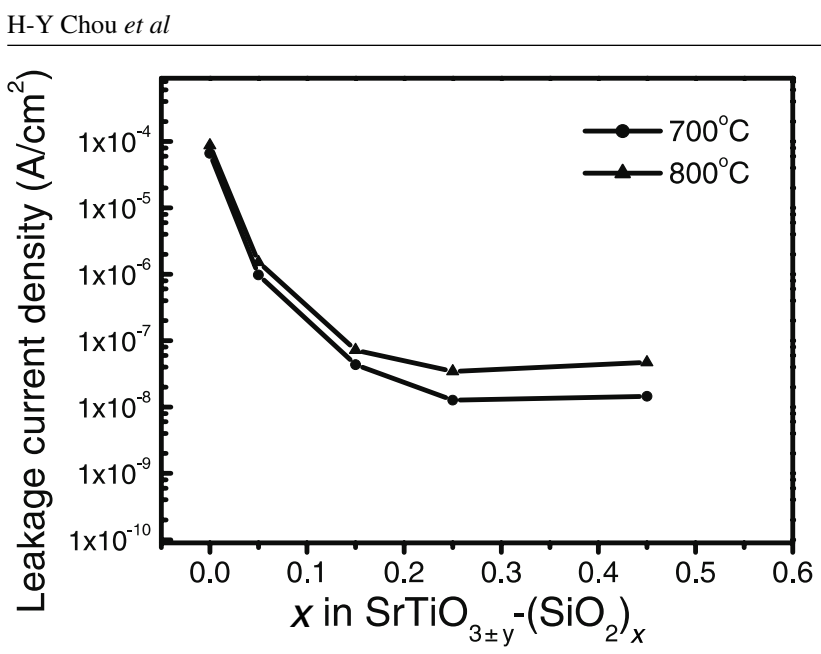

Figure 8. Leakage current density as a function of $x$ in $\mathrm{SrTiO}_{(3 \pm y)}-\left(\mathrm{SiO}_{2}\right)_{x}$ thin films annealed at $700^{\circ} \mathrm{C}$ and $800^{\circ} \mathrm{C}$.

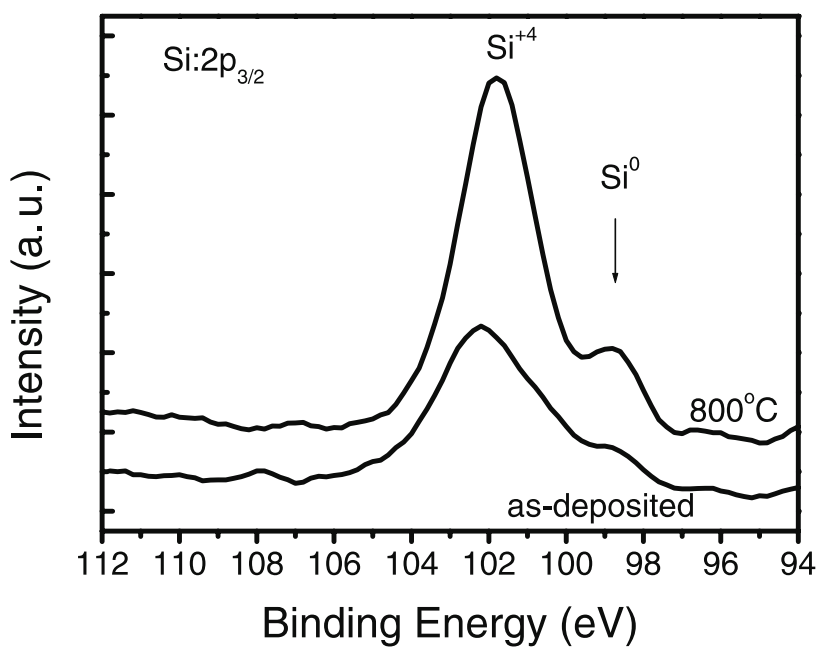

Figure 9. XPS spectrum of the Si $2 p 3 / 2$ for the $\mathrm{SrTiO}_{(3 \pm y)}-\left(\mathrm{SiO}_{2}\right)_{x}$ thin film with $x=0.45$ annealed at $800^{\circ} \mathrm{C}$.

indicated that the films with fine grain size had lower leakage current density than films with coarse gain size [13]. The leakage current density of the $\mathrm{SrTiO}_{(3 \pm y)}-\left(\mathrm{SiO}_{2}\right)_{x}$ thin film increases with increasing annealed temperature at the same Si content owing to the improved crystallinity and larger grain size in higher temperature annealed film. The leakage current of the films with $x$ value over 0.25 annealed at the same temperature does not decrease, but instead slightly increases with increasing $x$. This could be due to the segregation of the conductive Si. This explanation can be supported by the XPS spectrum of the Si $2 \mathrm{p}$ peak obtained from $x=0.45$ thin film deposited at $400^{\circ} \mathrm{C}$ and annealed at $800^{\circ} \mathrm{C}$ (as shown in figure 9). The spectrum clearly shows the $\mathrm{Si}^{+4}$ and $\mathrm{Si}^{0}$ peak simultaneously. The $\mathrm{Si}^{+4}$ peak represents the $\mathrm{Si}-\mathrm{O}$ bonding, but the $\mathrm{Si}^{0}$ peak comes mainly from segregation. The segregation of conductive Si leads to the leakage current density increase.

The relation of leakage current density versus electric field of $\mathrm{SrTiO}_{(3 \pm y)}-\left(\mathrm{SiO}_{2}\right)_{x}$ thin films with $x=0.25$ and annealed at various temperatures is shown in figure 10 . The films annealed at $700^{\circ} \mathrm{C}$ have a leakage current of lower than

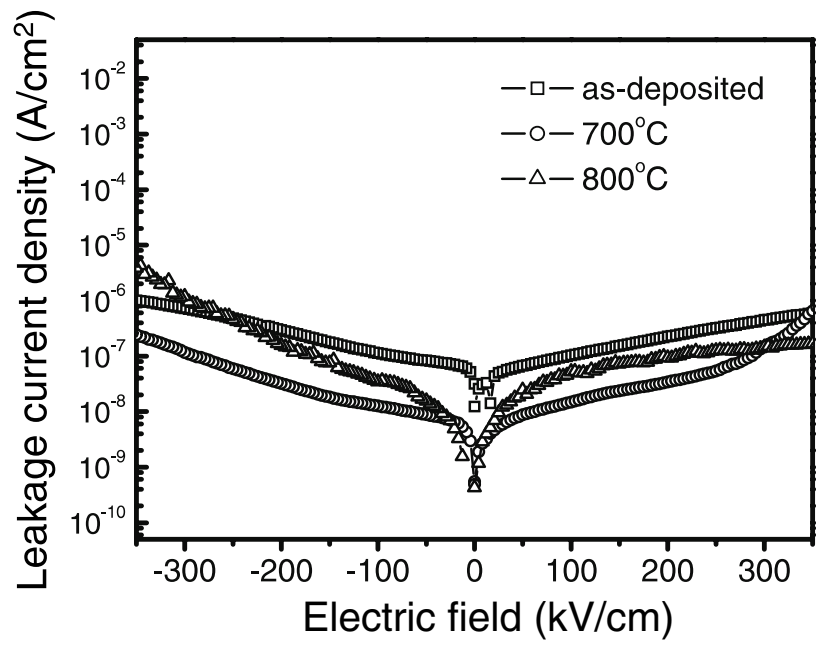

Figure 10. Curves of leakage current density versus electric field for $\mathrm{SrTiO}_{(3 \pm y)}-\left(\mathrm{SiO}_{2}\right)_{x}$ thin film with $x=0.25$ annealed at various temperatures indicated.

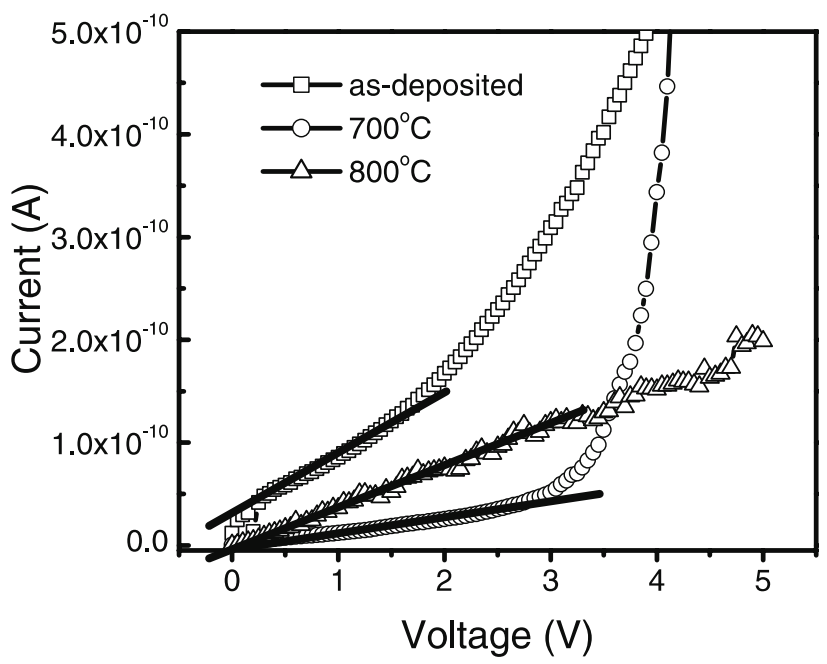

Figure 11. Current versus voltage plots of $\operatorname{SrTiO}_{(3 \pm y)}-\left(\mathrm{SiO}_{2}\right)_{x}$ thin films at various temperatures indicated.

$10^{-7} \mathrm{~A} \mathrm{~cm}^{-2}$ at $100 \mathrm{kV} \mathrm{cm}^{-1}$. The as-deposited film has a higher leakage current, probably owing to carbon residue. The leakage current density of the thin film annealed at $700^{\circ} \mathrm{C}$ is lower than that annealed at $800^{\circ} \mathrm{C}$, which is attributed to larger size grains that existed in the higher-temperature annealed film.

Figure 11 shows the plots of positive $I$ (current) versus $V$ (voltage) characteristics of the films annealed at various temperature in the MIM capacitor. It indicates the linear relationship between $I$ and $V$ existed at the low voltage part of those plots of as-deposited, $700^{\circ} \mathrm{C}$ and $800^{\circ} \mathrm{C}$ annealed films, which means that the conduction of this region is an ohmic behaviour. In general, the Schottky or/and Poole-Frenkel mechanisms are used to explain current transportation in ferroelectric films at moderate and high fields [14-16]. If the carrier transport obeys the Schottky model the logarithm of the current depends linearly on the square root of the applied voltage. If the current is governed by the Poole-Frenkel model, then $\log (I / V)$ varied with the square root of the 


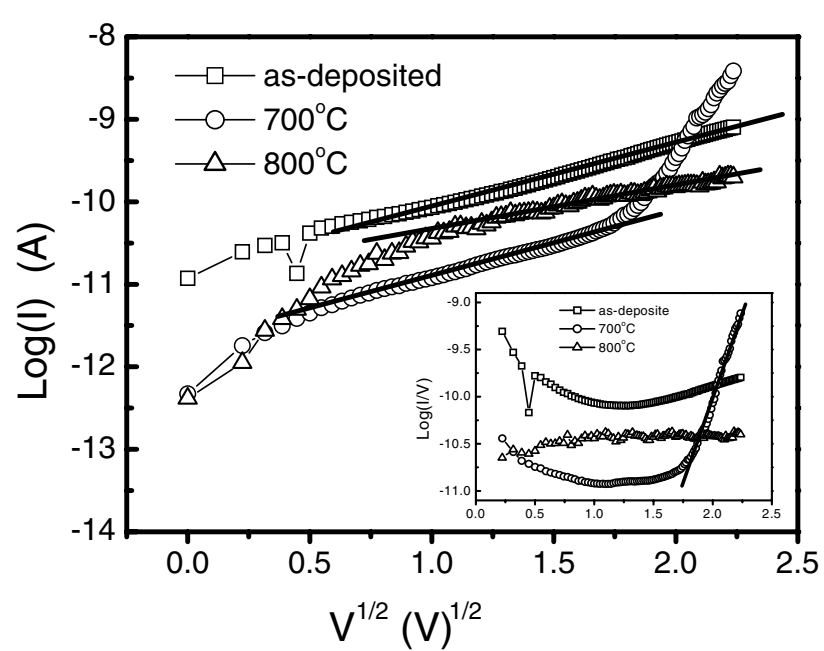

Figure 12. $\log (I)$ and $\log (I / V)$ versus $(V)^{1 / 2}$ plots of $\mathrm{SrTiO}_{(3 \pm y)}-\left(\mathrm{SiO}_{2}\right)_{x}$ thin film annealed at various temperatures indicated.

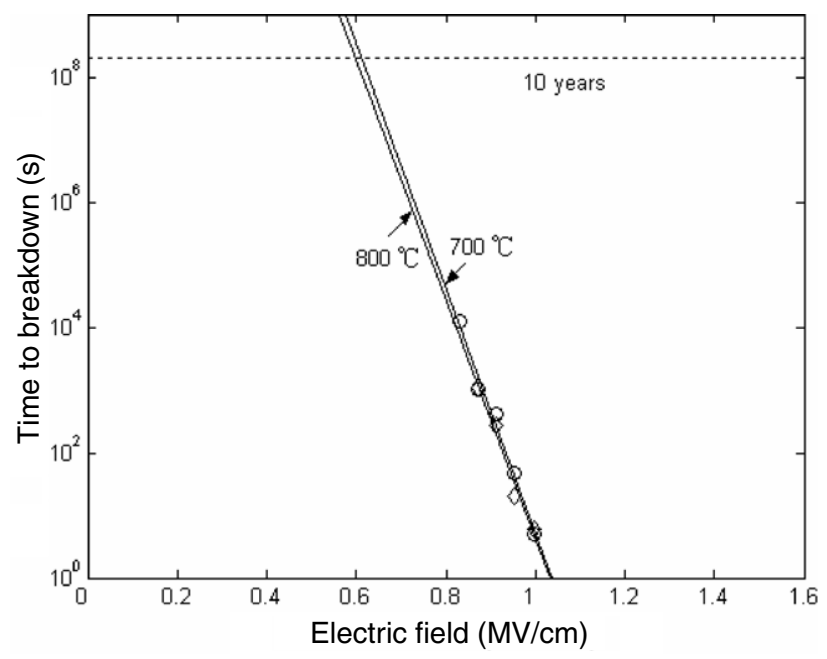

Figure 13. TDDB plots for $\mathrm{SrTiO}_{(3 \pm y)}-\left(\mathrm{SiO}_{2}\right)_{x}$ thin films with $x=0.25$ annealed at $700^{\circ} \mathrm{C}$ and $800^{\circ} \mathrm{C}$.

voltage is a linear function [17]. To identify the current conduction mechanism, $\log (I)$ (current) and $\log (I / V)$ versus $V^{1 / 2}$ (electric field) relationships of $\mathrm{SrTiO}_{(3 \pm y)}-\left(\mathrm{SiO}_{2}\right)_{x}$ thin films with $x=0.25$ are plotted and shown in figure 12. The as-deposited and $800^{\circ} \mathrm{C}$ annealed films at high voltage and $700^{\circ} \mathrm{C}$ annealed films at moderate voltage indicate a good linear relationship between $\log (I)$ and $V^{1 / 2}$, which suggests that the leakage current mechanism in these regions is Schottky emission. The leakage current of the film annealed at $700^{\circ} \mathrm{C}$ at high voltage indicate a good linearity in Poole-Frenkel plot (inset of figure 12), therefore, the mechanism in this region is the Poole-Frenkel emission.

The time-dependent dielectric breakdown (TDDB) plots (figure 13) indicate that the films operated at an electric field of above $0.6 \mathrm{MV} \mathrm{cm}^{-1}$ have a lifetime over 10 years. This reliability test also indicates that the lower the annealing temperature of the $\mathrm{SrTiO}_{(3 \pm y)}-\left(\mathrm{SiO}_{2}\right)_{x}$ thin films, the higher the breakdown field of the films. In spite of different leakage currents there are comparably small deviations in the TDDB behaviour.

\section{Conclusions}

The $110 \mathrm{~nm}$ thick $\mathrm{SrTiO}_{(3 \pm y)}-\left(\mathrm{SiO}_{2}\right)_{x}$ thin films were successfully prepared on a $\mathrm{Pt} / \mathrm{Ti} / \mathrm{SiO}_{2} / \mathrm{Si}$ substrate by using the CSD method and then annealing at various temperatures. The Si content and annealing temperature of $\operatorname{SrTiO}_{(3 \pm y)^{-}}$ $\left(\mathrm{SiO}_{2}\right)_{x}$ thin films play an important role in determining the state of crystallinity and electrical and dielectric properties. The crystallization temperature of the $\operatorname{SrTiO}_{(3 \pm y)}-\left(\mathrm{SiO}_{2}\right)_{x}$ thin films decreases with increasing $x$ value. The Si content of $\mathrm{SrTiO}_{(3 \pm y)}-\left(\mathrm{SiO}_{2}\right)_{x}$ thin film depresses the grain growth and improves the density of the thin film. The crystalline phase and dielectric constant of STO thin film all gradually increase with annealing temperature. The leakage current density and dielectric constant of $\mathrm{SrTiO}_{(3 \pm y)}-\left(\mathrm{SiO}_{2}\right)_{x}$ thin films decrease with increasing $\mathrm{Si}$ content. $\mathrm{SrTiO}_{(3 \pm y)}-\left(\mathrm{SiO}_{2}\right)_{x}$ thin films with $x=0.25$ annealed at $700^{\circ} \mathrm{C}$ have high dielectric constant and low leakage current of 94.8 and $1.27 \times 10^{-8} \mathrm{~A} \mathrm{~cm}^{-2}$, respectively. The TDDB curve indicates that the $\operatorname{SrTiO}_{(3 \pm y)^{-}}$ $\left(\mathrm{SiO}_{2}\right)_{x}$ films with $x=0.25$ annealed at $700^{\circ} \mathrm{C}$ and $800^{\circ} \mathrm{C}$ operated at an electric field of $0.6 \mathrm{MV} \mathrm{cm}^{-1}$ have an expected lifetime of over 10 years.

\section{Acknowledgment}

The authors gratefully appreciate the financial support received from the National Science Council of the Republic of China under contract no. NSC 92-2215-E009-016.

\section{References}

[1] Ezhilvalavan S and Tseng T Y 1999 J. Mater. Sci.: Mater. Electron. 109

[2] Gusev E P, Copel M, Cartier W, Baumvol I J R, Krug C and Gribelyuk M A 2000 Appl. Phys. Lett. 76176

[3] Mori H and Ishiwara H 1991 Japan. J. Appl. Phys. 30 L1415

[4] Lucovsky G and Rayner G B Jr 2000 Appl. Phys. Lett. 772912

[5] Harris H, Choi K, Medhta N, Chandolu A, Biswas N, Kipshidze G, Nikishin S, Gangopadhyay S and Tempkin $\mathrm{H}$ 2002 Appl. Phys. Lett. 811065

[6] Xu Z, Houssa M, De Gendt S and Heyns M 2002 Appl. Phys. Lett. 801975

[7] Liu C Y, Lue H T and Tseng T Y 2002 Appl. Phys. Lett. 81 4416

[8] Russack M A, Jahnes C V and Katz P E 1989 J. Vac. Sci. Technol. A 71248

[9] Neumayer D A and Cartier E 2001 J. Appl. Phys. 901801

[10] Thomas R, Dube D C, Kamalasanan M N, Chandra S and Bhalla A S 1997 J. Appl. Phys. 824484

[11] Radhakrishnan K, Tan C L, Zheng H Q and Ng G I 2000 J. Vac. Sci. Technol. A 181638

[12] Park M B, Cho N H and Kim C D 2002 J. Electroceram. 937

[13] Kim N K, Yoon S G, Lee W J and Kim H G 1997 J. Mater. Res. 121160

[14] Sze S M 1969 Physics of Semiconductor Devices (New York: Wiley) p 492

[15] Ezhilvalavan S and Tseng T Y 1998 J. Appl. Phys. 834797

[16] Tsai M S and Tseng T Y 1998 J. Electrochem. Soc. 1452853

[17] Mikhaelashvili V, Betzer Y, Prudnikov I, Orenstein M, Ritter D and Eisenstein G 1998 J. Appl. Phys. 846747 